\title{
Ionic Liquid Catalyzed Convenient Synthesis of Imidazo[1,2-a]quinoline under Sonic Condition
}

\author{
Devji S. Patel, Jemin R. Avalani and Dipak K. Raval* \\ Department of Chemistry, Sardar Patel University, Vallabh Vidyanagar 388 120, Gujarat, India
}

\begin{abstract}
Um protocolo eficiente para a síntese de derivados imidazol-[1,2- $a$-quinolina a partir de aldeídos, enaminonas ou malononitrila e utilizando como catalisador acetato de 1,8-diazabiciclo[5.4.0]undec-7-en-8-ium ([DBU][Ac]) sob irradiação de ultrassom é descrito. Em comparação com outras metodologias, esta apresenta as vantagens de um tratamento reacional mais simples, condições reacionais mais suaves, rendimentos elevados e um procedimento ambientalmente aceitável.
\end{abstract}

An efficient protocol for the synthesis of imidazo[1,2- $a]$ quinoline from aldehydes, enaminones, and malononitrile using 1,8-diazabicyclo[5.4.0]-undec-7-en-8-ium acetate $([\mathrm{DBU}][\mathrm{Ac}])$ as a catalyst under ultrasound irradiation is described. Compared with other methods, this new method has the advantages of easier work-up, milder reaction conditions, high yields and environmentally benign procedure.

Keywords: ionic liquid, imidazo[1,2- $a$ ]quinoline, ([DBU][Ac]), green catalyst, multicomponent reaction, one pot synthesis

\section{Introduction}

The synthesis of organic compounds is one of the most important objectives in modern drug discovery. Organic reactions should be fast and the targeted products should be easily separated in high purity and yields. In this regard, there is much attention paid in the development of new processes and new synthetic approach. From this point of view, non-classical methods such as microwave-assisted synthesis, ultrasonic irradiation and supercritical fluids find relevance as attractive methods to achieve these goals. ${ }^{1}$

Bridgehead nitrogen heterocycles are of interest because they constitute an important class of natural products, many of which exhibit useful biological activity. ${ }^{2,3}$ The interest in bicyclic 5-6 systems with one ring junction and one extra nitrogen atom stems from imidazo[1,2-a] quinoline ring systems found in many biologically active compounds. Imidazo[1,2-a]quinoline is a synthetically designed scaffold with a broad range of biological activities. Some of its derivatives have pharmacological properties such as contraceptive, ${ }^{4}$ hypotensive, ${ }^{5}$ antiallergic and antiasthmatic agents. ${ }^{6}$ Several prospective nonsedative anxiolytic agents with the imidazoquinoline structure have been discovered. ${ }^{7}$

*e-mail: dipanalka@yahoo.com
In the last few years, the development of synthetic protocol employing ultrasound irradiation has led to an epoch-making change in organic reactions. Using ultrasound irradiation, a wide variety of heterocycles can be synthesized under milder conditions, within shorter reaction time and in higher yield. ${ }^{8}$ Recently, ionic liquids (ILs) have emerged as the potential for novel changes to synthetic routes and unit operations in research as well as in the chemical industry. Although the ionic liquid was initially introduced as an alternative green reaction medium, today it has marched far beyond showing its important role in controlling the reactions as catalyst. ${ }^{9}$ In recent times, basic ionic liquids have aroused unprecedented interest because they showed more advantages, such as catalytic efficiency and recyclability.

Literature survey revealed that there exist only two multicomponent reports by Tu et al. ${ }^{10}$ and Ahmadi et al. ${ }^{11}$ for the synthesis of imidazo[1,2-a]quinoline under microwave irradiation and conventional heating, respectively. However, the generality of the existing reports is somewhat vitiated by the severe reaction conditions and the catalysts in the context of green synthesis. Thus, the development of an efficient and green approach for the preparation of heterocycles containing bridgehead nitrogen sought highly desirable. Prompted by these facts and as a part of our ongoing programme on 


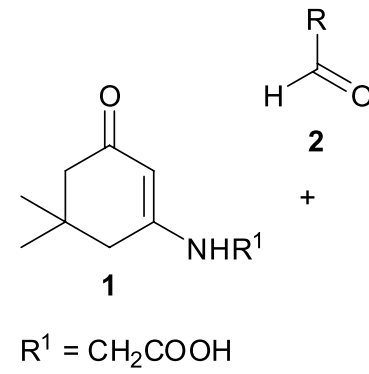

Scheme 1. Synthesis of imidazo[1,2-a]quinoline derivatives.

multicomponent reactions, ${ }^{12}$ an efficient and convenient protocol for the synthesis of imidazo[1,2-a] quinoline derivatives via condensation reaction of aldehydes, enaminones and malononitrile in the presence of 1,8-diazabicyclo[5.4.0]-undec-7-en-8-ium acetate ([DBU][Ac]) under ultrasound irradiation in methanol has been accomplished (Scheme 1).

\section{Results and Discussion}

Our group successfully synthesized [DBU][Ac] under ultrasound irradiation within $90 \mathrm{~min}$. The same transformation under conventional conditions as reported by Chen et al. ${ }^{13}$ took $48 \mathrm{~h}$ to complete.

Initial studies were focused on one-pot three-component condensation of 4-nitrobenzaldehyde, malononitrile and enaminone at ambient temperature using different amount of ionic liquid in methanol as co-solvent (Table 1, entries 1-5). It indicates that the reaction proceeded well in the presence of $6.25 \mathrm{~mol} \%$ of [DBU][Ac] as the catalyst.

Different organic solvents were also screened to see their efficiency in the reaction. As shown in Table 1, it seems that the reaction proceeds better in protic organic solvents than in aprotic organic solvents. Under solvent free condition, the reaction proceeded with poor yield (Table 1, entry 12). The reaction in water as the co-solvent proceeded largely up to the intermediate Knoevenagel product (Table 1, entry 7). Thin layer chromatography (TLC) of the reaction mixture indicated the presence of unreacted enaminone. This may be because of poor solubility of the reactants not favoring homogeneity required for fruitful collisions for product formation. This clearly indicates that proper solvent is essential for shifting the reaction to the product side. As per our observation, methanol gave superior homogeneity to the reaction mass. Therefore, it was opted as a co-solvent.

Table 1. Synthesis of $\mathbf{4 a}$ under various conditions

\begin{tabular}{|c|c|c|c|c|c|c|}
\hline entry & Ionic liquid & Co-solvent & $\mathrm{Mol} \%$ & Reaction condition & time / min & Yield / \% \\
\hline 1 & [DBU][Ac] & methanol & 0 & $\mathrm{RT})))$, & 180 & 0 \\
\hline 2 & {$[\mathrm{DBU}][\mathrm{Ac}]$} & methanol & 1.64 & $\mathrm{RT}$, ))) & 125 & 61 \\
\hline 3 & {$[\mathrm{DBU}][\mathrm{Ac}]$} & methanol & 3.23 & $\mathrm{RT}$, ))) & 105 & 67 \\
\hline 4 & {$[\mathrm{DBU}][\mathrm{Ac}]$} & methanol & 6.25 & $\mathrm{RT}$, ))) & 90 & 74 \\
\hline 5 & {$[\mathrm{DBU}][\mathrm{Ac}]$} & methanol & 9.09 & $\mathrm{RT})))$, & 90 & 76 \\
\hline 6 & {$[\mathrm{DBU}][\mathrm{Ac}]$} & ethanol & 6.25 & $\mathrm{RT}, \mathrm{)}))$ & 95 & 70 \\
\hline 7 & {$[\mathrm{DBU}][\mathrm{Ac}]$} & water & 6.25 & $\mathrm{RT}$, ))) & 160 & $\operatorname{trace}^{\mathrm{a}}$ \\
\hline 8 & {$[\mathrm{DBU}][\mathrm{Ac}]$} & THF & 6.25 & RT, ))) & 120 & 36 \\
\hline 9 & {$[\mathrm{DBU}][\mathrm{Ac}]$} & MDC & 6.25 & $\mathrm{RT}, \mathrm{)}))$ & 160 & 28 \\
\hline 10 & {$[\mathrm{DBU}][\mathrm{Ac}]$} & acetonitrile & 6.25 & $\mathrm{RT}$, ))) & 150 & 33 \\
\hline 11 & {$[\mathrm{DBU}][\mathrm{Ac}]$} & toluene & 6.25 & $\mathrm{RT},()))$ & 160 & 25 \\
\hline 12 & {$[\mathrm{DBU}][\mathrm{Ac}]$} & solvent free & 6.25 & $\mathrm{RT})))$, & 120 & $35^{\mathrm{a}}$ \\
\hline 13 & DBU & methanol & 6.25 & $\mathrm{RT}$, ))) & 90 & 35 \\
\hline 14 & {$[\mathrm{DBU}][\mathrm{Ac}]$} & methanol & 6.25 & $\left.\left.\left.50{ }^{\circ} \mathrm{C},\right)\right)\right)$ & 75 & 93 \\
\hline 15 & {$[\mathrm{DBU}][\mathrm{Ac}]$} & methanol & 6.25 & $\left.\left.\left.60^{\circ} \mathrm{C},\right)\right)\right)$ & 75 & 94 \\
\hline 16 & {$[\mathrm{DBU}][\mathrm{Ac}]$} & Methanol & 6.25 & reflux, ))) & 75 & 94 \\
\hline 17 & [DBU][Ac] & methanol & 6.25 & reflux & 120 & 60 \\
\hline
\end{tabular}

${ }^{a}$ Enaminone remains sparingly soluble under this condition; RT: room temperature; ))): ultrasound irradiation. 
To optimize the temperature of the reaction, a set of reactions was carried out using $6.25 \mathrm{~mol} \%$ of [DBU][Ac] at various temperatures under ultrasound irradiation (Table 1, entries 13-16). The model reaction was also studied under reflux without sonication (Table 1, entry 17). The yield of $\mathbf{4 a}$ was very low (60\%) as compared to $94 \%$ under sonication at reflux. The results clearly show that $50{ }^{\circ} \mathrm{C}$ is an effective temperature in terms of reaction time and yield. It became apparent that the ultrasound irradiation accelerated this transformation under same conditions. The reason may be the phenomenon of cavitation produced by ultrasound. ${ }^{8,14}$ Hence, the conditions of entry 14, shown in Table 1, were selected as the optimized reaction conditions.

It was extended the scope and general applicability of the methodology to a broad range of structurally diverse aromatic aldehydes with malononitrile and enaminone under optimized reaction conditions. Results are shown in Table 2. The electronic nature of the substituents on the aromatic ring did not show any strong effect in terms of yields under these reaction conditions. Aromatic aldehydes containing both electron-withdrawing and electron-donating groups gave good to excellent yields.

Table 2. Synthesis of imidazo[1,2-a]quinolone derivatives under ultrasound irradiation

\begin{tabular}{lccc}
\hline entry & $\mathrm{R}$ & time / min & Yield $/ \%$ \\
\hline $\mathbf{4 a}$ & $4-\mathrm{NO}_{2} \mathrm{C}_{6} \mathrm{H}_{4}$ & 75 & 93 \\
$\mathbf{4 b}$ & $4-\mathrm{FC}_{6} \mathrm{H}_{4}$ & 45 & 91 \\
$\mathbf{4 c}$ & $4-\mathrm{ClC}_{6} \mathrm{H}_{4}$ & 45 & 90 \\
$\mathbf{4 d}$ & $\mathrm{C}_{6} \mathrm{H}_{5}$ & 50 & 94 \\
$\mathbf{4 e}$ & $3-\mathrm{NO}_{2} \mathrm{C}_{6} \mathrm{H}_{4}$ & 75 & 92 \\
$\mathbf{4 f}$ & $2-\mathrm{NO}_{2} \mathrm{C}_{6} \mathrm{H}_{4}$ & 60 & 93 \\
$\mathbf{4 g}$ & $4-\mathrm{OCH}_{3} \mathrm{C}_{6} \mathrm{H}_{4}$ & 75 & 88 \\
$\mathbf{4 h}$ & $2-\mathrm{ClC}_{6} \mathrm{H}_{4}$ & 55 & 90 \\
$\mathbf{4 i}$ & $4-\mathrm{BrC}_{6} \mathrm{H}_{4}$ & 60 & 90 \\
$4 \mathbf{j}$ & $2,4-\left(\mathrm{Cl}_{2} \mathrm{C}_{6} \mathrm{H}_{3}\right.$ & 60 & 91 \\
$\mathbf{4 k}$ & $3,4,5-\left(\mathrm{OCH}_{3}\right)_{3} \mathrm{C}_{6} \mathrm{H}_{2}$ & 60 & 92 \\
$\mathbf{4 l}$ & $4-(\mathrm{CH} 3)_{2} \mathrm{NC}_{6} \mathrm{H}_{4}$ & 90 & 86 \\
\hline
\end{tabular}

Reaction conditions: enaminone (10 mmol), aromatic aldehyde $(10 \mathrm{mmol})$, malononitrile $(10 \mathrm{mmol})$ and [DBU][Ac] $(6.25 \mathrm{~mol} \%)$ under sonication at $50{ }^{\circ} \mathrm{C}$ in methanol as co-solvent; ${ }^{a}$ isolated yield.

To investigate the catalytic efficiency of recycled ionic liquid, five successive cycles of the model reaction were run under the optimal reaction conditions using recycled IL from the previous run (Figure 1). The activity of the catalyst did not show any significant decrease in the yields after five successive runs for the model reaction. It was revealed that the catalyst displayed very good reusability.

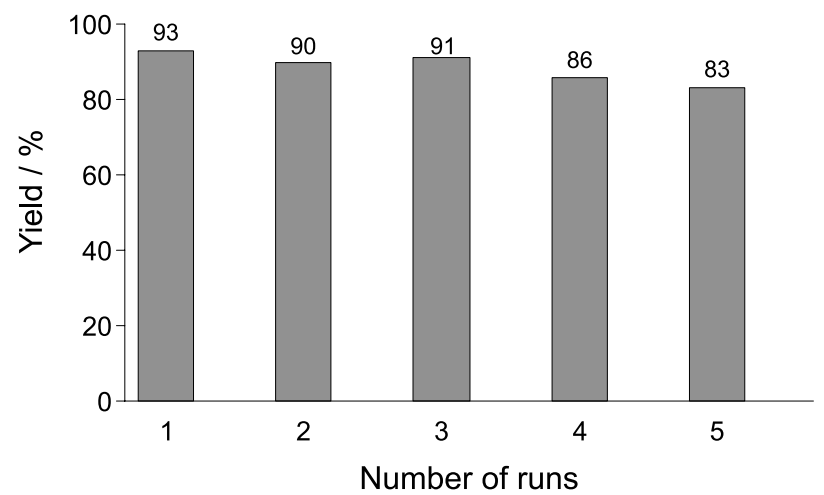

Figure 1. Recyclability of ionic liquid.

\section{Conclusion}

The report demonstrates an elegant protocol for the synthesis of imidazo[1,2-a]quinoline catalyzed by [DBU][AC] under ultrasonic irradiation using methanol as co-solvent. The synergy of sonication and ionic liquid in the three-component condensation brought up advantages likes simple procedure, milder reaction condition, easier workup and improved yield over other existing methods. The use of [DBU][AC] a non-toxic, economical and reusable catalyst renders this method greener and cleaner, making it a convenient alternative to the existing procedures.

\section{Experimental}

\section{Chemicals and apparatus}

All chemicals were of research grade and used without further purification. Enaminone was synthesized by reported method..$^{10}$ The reactions were performed in D-compact ultrasonic cleaner with a frequency of $50 \mathrm{kHz}$ and power $250 \mathrm{~W}$. Mass spectra on a Shimadzu GCMS QP 2010 instrument and ${ }^{1} \mathrm{H}$ and ${ }^{13} \mathrm{C}$ nuclear magnetic resonance (NMR) spectra were recorded on Bruker Avance $400 \mathrm{MHz}$ spectrometer in DMSO- $d_{6}$ with TMS as an internal standard.

Synthesis of Imidazo[1,2-a]quinoline derivatives under ultrasound irradiation

The ionic liquid, 1,8-diazabicyclo[5.4.0]-undec7 -en-8-ium acetate [DBU][Ac] $(6.25 \mathrm{~mol} \%)$, was added to a mixture of enaminone $\mathbf{1}(10 \mathrm{mmol})$, aldehyde $\mathbf{2}$ $(10 \mathrm{mmol})$ and malononitrile $3(10 \mathrm{mmol})$ in methanol $(5 \mathrm{~mL})$. The reaction mixture was irradiated at $50{ }^{\circ} \mathrm{C}$ by ultrasound for required time. After completion of reaction (as indicated by TLC), a solid product gradually 
formed was poured onto crushed ice (20 g) and stirred for 15-20 min. The solid separated was filtered through a sintered funnel under suction, washed with ice-cold water $(15 \mathrm{~mL})$ and then recrystallized from hot ethanol to afford pure imidazo[1,2- $a]$ quinoline derivatives. The aqueous filtrate was then subjected to distillation at $80{ }^{\circ} \mathrm{C}$ under reduced pressure $(10 \mathrm{mmHg}$ ) to leave behind the IL in almost complete recovery. Thus, recycled IL was active enough to be reused in subsequent reactions.

\section{Spectral data for selected compounds}

5-(4-Nitrophenyl)-1,2,3,5,6,7,8,9-octahydro-8,8-dimethyl2,6-dioxoimidazo[1,2-a]quinoline-4-carbonitrile (4a)

${ }^{1} \mathrm{H}$ NMR (400 MHz, DMSO- $\left.d_{6}\right) \delta 12.048(\mathrm{~s}, 1 \mathrm{H})$, $8.164(\mathrm{~d}, 2 \mathrm{H}, J 8.4 \mathrm{~Hz}), 7.569(\mathrm{~d}, 2 \mathrm{H}, J 8.4 \mathrm{~Hz}), 4.707$ (s, $1 \mathrm{H}), 4.421(\mathrm{~s}, 2 \mathrm{H}), 2.585-2.428(\mathrm{~m}, 2 \mathrm{H}), 2.206(\mathrm{~d}, 1 \mathrm{H}$, $J$ 16.4 Hz), 2.023 (d, 1H, J 16.0 Hz), 1.055 (s, 3H), 0.893 $(\mathrm{s}, 3 \mathrm{H}) ;{ }^{13} \mathrm{C}$ NMR (100 MHz, DMSO- $\left.d_{6}\right) \delta 194.3,170.7$, 153.3, 149.6, 146.8, 129.2, 124.0, 118.3, 108.8, 62.9, 56.5, 49.9, 49.4, 38.7, 38.0, 32.3; ESI-MS m/z 379.0 [M + H $]^{+}$. Anal. Calc. for $\mathrm{C}_{20} \mathrm{H}_{18} \mathrm{~N}_{4} \mathrm{O}_{4}\left(378.38 \mathrm{~g} \mathrm{~mol}^{-1}\right)$ : C, 63.48; $\mathrm{H}$, 4.79; N, 14.81\%. Found: C, 63.27; H, 4.86; N, 14.95\%.

\section{5-(4-Fluorophenyl)-1,2,3,5,6,7,8,9-octahydro-8,8-dimethyl-} 2,6-dioxoimidazo[1,2-a]quinoline-4-carbonitrile (4b)

${ }^{1} \mathrm{H}$ NMR $\left(400 \mathrm{MHz}\right.$, DMSO- $\left.d_{6}\right) \delta 11.959(\mathrm{~s}, 1 \mathrm{H}), 7.292$ (s, 2H), $7.103(\mathrm{t}, 2 \mathrm{H}, J 8.4 \mathrm{~Hz}), 4.534(\mathrm{~s}, 1 \mathrm{H}), 4.401$ (s, 2H), 2.566-2.398 (m, 2H), 2.192 (d, 1H, J 16.0 Hz), 2.017 $(\mathrm{d}, 1 \mathrm{H}, J 16.0 \mathrm{~Hz}), 1.047$ (s, 3H), $0.886(\mathrm{~s}, 3 \mathrm{H}) ;{ }^{13} \mathrm{C}$ NMR $\left(100 \mathrm{MHz}\right.$, DMSO- $\left.d_{6}\right) \delta 194.3,170.8,160.3,149.2,148.9$, $142.3,136.1,130.0,129.3,118.6,116.2,114.8,109.7,63.9$, 50.1, 49.3, 38.6, 32.2; ESI-MS m/z 351.8 [M + H] ${ }^{+}$. Anal. Calc. for $\mathrm{C}_{20} \mathrm{H}_{18} \mathrm{FN}_{3} \mathrm{O}_{2}\left(351.37 \mathrm{~g} \mathrm{~mol}^{-1}\right)$ : C, 68.36; H, 5.16; $\mathrm{N}, 11.96 \%$. Found: C, 68.67; H, 5.07; N, $11.74 \%$.

\section{Supplementary Information}

Synthesis of [DBU][Ac] under ultrasound irradiation, analytical data and spectra of all synthesized compounds are available as a supplementary material, free of charge at http://jbcs.sbq.org.br as PDF file.

\section{Acknowledgement}

Authors thank Head, Department of Chemistry, Sardar Patel University for infrastructure and other facilities. DKR thanks Sardar Patel University, Vallabh Vidyanagar (India) for allotment of research seed grant 2011-12.

\section{References}

1. Nüchter, M.; Ondruschka, B.; Jungnickel, A.; Müller, U.; J. Phys. Org. Chem. 2000, 13, 579.

2. Swinbourne, F. J.; Hunt, J. H.; Klinkert, G. In Advances in Heterocyclic Chemistry, vol. 23; Katritzky, A. R.; Boulton, A. J., eds.; Academic Press: London, 1979.

3. Katritzky, A. R.; Rees, C. W.; Scriven, E. F. V.; Comprehensive Heterocyclic Chemistry; Pergamon Press: London, 1996.

4. Omodei, A. S.; Toia, E.; Galliani, G.; Lerner, L. J.; Ger. Offen. 2551868, 1976 (CA 85:192731p).

5. Black, R. M.; GB 1488412, 1978 (CA 88:121177p).

6. Ager, I. R.; Ramm, J. P.; Ger. Offen. 2802493, 1978 (CA 89:180001v); Kadin, S.B.; US 4075343, 1978 (CA 88:190834n); Ager, I. R.; Barnes, A. C.; Danswan, G. W.; Hairsine, P. W.; Kay, D. P.; Kennewell, P. D.; Matharu, S. S.; Miller, P.; Robson, P.; J. Med. Chem. 1988, 31, 1098.

7. Clements, S. J.; Danswan, G.; Gardner, C. R.; Matharu, S. S.; Murdoch, R.; Tully, W. R.; Westwood, R.; J. Med. Chem. 1988, 31, 1220.

8. Mason, T. J.; Peters, D.; Practical Sonochemistry: Uses and Applications of Ultrasound; Horwood Publishing: Chischester, UK, 2002; Li, J.-T.; Bian, Y.-J.; Zang, H.-J.; Li, T.-S.; Synth. Commun. 2002, 32, 547.

9. dos Santos, M. R.; Diniz, J. R.; Arouca, A. M.; Gomes, A. F.; Gozzo, F. C.; Tamborim, S. M.; Parize, A. L.; Suarez, P. A. Z.; Neto, B. A. D.; ChemSusChem 2012, 5, 716.

10. Tu, S.; Li, C.; Li, G.; Cao, L.; Shao, Q.; Zhou, D.; Jiang, B.; Zhou, J.; Xia, M.; J. Comb. Chem. 2007, 9, 1144.

11. Ahmadi, S. J.; Hosseinpour, M.; Sadjadi, S.; Synth. Commun. 2011, 41, 426.

12. Dadhania, A. N.; Patel, V. K.; Raval, D. K.; J. Braz. Chem. Soc. 2011, 22, 511; Dadhania, A. N.; Patel, V. K.; Raval, D. K.; C.R. Chimie. 2012, 15, 378.

13. Ying, A. G.; Wang, L. M.; Wang, L. L.; Chen, X. Z.; Ye, W. D.; J. Chem. Res. 2010, 30.

14. Li, J. T.; Wang, S. X.; Chen, G. F.; Li, T. S.; Curr. Org. Synth. 2005, 2, 415 . 